\title{
Role Emerging Placements in Undergraduate Occupational Therapy Training: A Case Study
}

\author{
Martin Fitzgerald \\ University of Bradford, m.fitzgerald@bradford.ac.uk
}

Abigail Kate Smith

Bradford Teaching Hospital NHS Foundation Trust.

Nazman Rehman

Bradford Teaching Hospital NHS Foundation Trust

Michelle Taylor

The Rockwell Community Centre

Follow this and additional works at: https://nsuworks.nova.edu/ijahsp

Part of the Community Health Commons, Curriculum and Instruction Commons, Educational Assessment, Evaluation, and Research Commons, and the Higher Education Commons

\section{Recommended Citation}

Fitzgerald M, Smith AK, Rehman N, Taylor M. Role Emerging Placements in Undergraduate Occupational Therapy Training: A Case Study. The Internet Journal of Allied Health Sciences and Practice. 2017 Jan 01;15(4), Article 7.

This Case Study is brought to you for free and open access by the College of Health Care Sciences at NSUWorks. It has been accepted for inclusion in Internet Journal of Allied Health Sciences and Practice by an authorized editor of NSUWorks. For more information, please contact nsuworks@nova.edu. 


\title{
Role Emerging Placements in Undergraduate Occupational Therapy Training: A Case Study
}

\begin{abstract}
Purpose: Role-emerging placements in occupational therapy training are contributing to professional and workforce development because of their strong occupational focus and placement of students in emerging practice. This manuscript explores how one role-emerging placement challenged and developed student theoretical and clinical skills, presented new ways of working at the recipient site, and enhanced service delivery. Methods: The background to role-emerging placements in occupational therapy is explored through the use of a case study which reflects on and analyses how the assessment and treatment of occupation enhanced service delivery at a local, non-traditional site. Eight students in England developed and ran a psycho-education group to support the occupational needs of female service users who have experienced domestic abuse. Results There was an overall increase in self-esteem scores and an expressed increase in knowledge and understanding by participants. Students reported developing a deeper understanding of occupation, and the hosts identified the student's clinical skills as unique contributors to service delivery. Conclusion: By focusing on occupation, role-emerging placements draw on the roots of the profession and anchor its future to the theoretical foundations of its past. However, in order to employ occupational therapists, these organisations need to understand what the occupational therapy profession can offer them.
\end{abstract}

\section{Author Bio(s)}

Martin Fitzgerald, BA, BSc, MSc, PGCert, FHE is an Occupational Therapy Lecturer at the University of Bradford, West Yorkshire and the Head Occupational Therapist at the Rehabilitation and High Support Directorate, Pennine Care, NHS Foundation Trust, Manchester, UK.

Abigail Kate Smith was an occupational therapy student at the University of Bradford, West Yorkshire, UK, from 2012 to 2015. Abigail is now working as an occupational therapist at Bradford Teaching Hospital NHS Foundation Trust.

Nazman Rehman was an occupational therapy student at the University of Bradford, West Yorkshire, UK, from 2012 to 2015. Nazman is now working as an occupational therapist at Bradford Teaching Hospital NHS Foundation Trust.

Michelle Taylor is the Self Help Project Lead at The Rockwell Community Centre in Bradford, West Yorkshire, UK. 


\title{
IUAHSP \\ The Internet Joumnal of Allied Health Sciences and Practice \\ Dedicated to allied health professional practice and education \\ Vol. 15 No. 4 ISSN 1540-580X \\ Role Emerging Placements in Undergraduate Occupational Therapy Training: A Case Study
}

\author{
Martin Fitzgerald, BA, BSc, MSc, PGCert, FHE ${ }^{1}$ \\ Abigail Kate Smith, $\mathrm{OT}^{2}$ \\ Michelle Taylor ${ }^{3}$ \\ Nazman Rehman, OT $^{2}$
}

1. University of Bradford

2. Bradford Teaching Hospital

3. The Rockwell Community Centre

United Kingdom

\begin{abstract}
Purpose: Role-emerging placements in occupational therapy training are contributing to professional and workforce development because of their strong occupational focus and placement of students in emerging practice. This manuscript explores how one role-emerging placement challenged and developed student theoretical and clinical skills, presented new ways of working at the recipient site, and enhanced service delivery. Methods: The background to role-emerging placements in occupational therapy is explored through the use of a case study which reflects on and analyses how the assessment and treatment of occupation enhanced service delivery at a local, non-traditional site. Eight students in England developed and ran a psycho-education group to support the occupational needs of female service users who have experienced domestic abuse. Results There was an overall increase in self-esteem scores and an expressed increase in knowledge and understanding by participants. Students reported developing a deeper understanding of occupation, and the hosts identified the student's clinical skills as unique contributors to service delivery. Conclusion: By focusing on occupation, role-emerging placements draw on the roots of the profession and anchor its future to the theoretical foundations of its past. However, in order to employ occupational therapists, these organisations need to understand what the occupational therapy profession can offer them.
\end{abstract}

\section{INTRODUCTION}

Practice placement education prepares the student for work in a professional and clinical context, helping them to develop professional identity, boundaries, and values. ${ }^{1,2}$ In traditional placements, students are required to identify and emulate the occupational therapist role. ${ }^{3}$ Education follows an apprenticeship model where students learn core professional and technical skills from their supervisor in established health or local authority settings. ${ }^{4,5} \mathrm{~A}$ role-emerging placement (REP) takes place when there is no established occupational therapy service and the student is supervised by site staff and an offsite fieldwork educator.6${ }^{9}$ Students are encouraged to explore, from an occupational perspective, how they could positively impact on the user's health and site's service delivery. ${ }^{3}$ These placements are designed to promote the role of occupational therapy while students explore the potential for the profession to meet service needs. ${ }^{7,9}$ Sustainability is an important part of REPs, and students are expected to leave an enduring legacy whereby their work, in some way, is continued by the service. ${ }^{3}$

Occupational therapy is changing; more and more graduates are finding employment in third sector settings. - $^{-10}$ For example, Thomas et al noted that only $51 \%$ of Australian and New Zealand occupational therapists work in government funded health care. ${ }^{10}$ The reasons for this are multi-factorial but reflect the changing health, social, and economic climate in which health care is delivered..$^{5}$ There is now a move away from curative, rehabilitative models of care to those of health promotion, health prevention, and the management of long-term conditions. ${ }^{6,8,9}$ Non-government, community-based organisations are now the

(c) The Internet Journal of Allied Health Sciences and Practice, 2017 
most common provider of these services, and are also, in the experience of this author, the most common recipients of REP students. ${ }^{7}$

The REP described in this paper took place at the University of Bradford's Faculty of Health Studies, Occupational Therapy Program, in the north of England. In the UK, students can study occupational therapy in a three-year undergraduate program, or if they have an existing undergraduate degree in appropriate subject areas, in a two-year, pre-registration master's degree course. At the University of Bradford, REPs take place in the third year of the three-year undergraduate program. Typically, two students are placed at a local organisation for three days a week for nine weeks. All third-year students have to participate in the REP. Students are assessed by the onsite supervisor and the fieldwork educator and receive a mark out of 100 . This mark contributes to their final degree grade.

Role-emerging placements have been supported by the University of Bradford since 2005. Each year, the School of Occupational Therapy holds a REP conference to organise the placements. The conference is attended by third year students, fieldwork educators, and the role-emerging site supervisors. Each site presents an overview of their service, and the students present an overview of occupational therapy and the role of occupation in supporting health and wellbeing. Over the next week, students choose and bid for the site placement. Fieldwork educators also have the opportunity to select the placement site they would like to supervise. A certain amount of negotiation and juggling takes place, particularly among the students, until each role-emerging site has two students, one clinical supervisor, and one site supervisor. Some years this process runs very smoothly and students get their first choice placement. In other years, students have to compromise and negotiate. At this time, there has not been a situation when student numbers have exceeded REP offers.

\section{METHOD \\ The REP Site}

The placement site is a community centre situated in Bradford, a city in the north of England. It serves a low socioeconomic community, providing a wide range of activities, groups, services, and opportunities for people to improve their lifestyle, health, and sense of wellbeing. In particular, the centre engages directly with families on low-incomes, children, young people, the elderly, lone parents, and the disabled so as to support them and to meet their expressed needs. The centre was the first REP choice for two third-year, female students; the onsite supervisor was the community centre's Self-Help Project Lead, and the fieldwork educator was from a government-funded National Health Service (NHS), Mental Health Trust.

\section{The Potential for Occupational Therapy}

The centre provided a weekly coffee morning for women who have experienced domestic violence. Participation varied but ranged from five to fifteen attendees each week. Participation was voluntary and the group's structure informal. While attending this group, the students identified the potential for occupational therapy. Many of the group participants experienced anxiety, stress, and low self-esteem. Many reported not being able to do the things they would like to do because they struggled to cope or manage. Anxiety, anger, and a propensity to aggressive outbursts when stressed or in difficult social situations was also common, and the women identified this as a major problem for them. These problems and issues were seen by the students as barriers to occupation, its remediation a role for occupational therapy, and an opportunity to meet previously unmet service need.

Typical of REPs, the students had to draw on evidence and literature beyond that specific to occupational therapy in order to plan their intervention. This was a challenge because the students could not utilise the established support mechanisms of a traditional placement or draw on existing practice within the site. Instead, they had to rely on occupational therapy frameworks, models, and interventions to interpret service user need and to plan their intervention. This typifies the key difference between a traditional placement and a REP and why REPs help prepare students for modern clinical practice.

\section{Rational for Intervention}

Low self-esteem, stress, anxiety, and maladaptive coping were identified by the students as key occupation barriers for participants and a symptom of their low occupational satisfaction. Poor self-esteem is a common symptom experienced by domestic violence survivors, which along with emotional and psychological trauma, can severely affect occupational performance. ${ }^{12,13}$ Cascardi and O'Leary as cited in Waldrop and Resick identified self-esteem as a stable construct and symptom of abuse that is associated with learned helplessness and less active forms of coping. ${ }^{17,18} \mathrm{~A}$ cycle of occupational decline is created where reduced active coping contributes to negative self-assessment of one's ability to cope, and this in turn contributes to a further decline in coping and occupational performance..$^{15}$ The premise for the intervention was therefore as follows: 1) By elevating the skills that support adaptive coping and self-esteem, the occupational performance of participants can be improved, and 2) Elevated occupational performance will in turn improve coping and self-esteem of participants. A similar rational was

() The Internet Journal of Allied Health Sciences and Practice, 2017 
employed by Cage in their pre-test / post-test investigation of the occupational performance, self-esteem, and quality of life of service users engaged in a recovery from substance abuse program. ${ }^{16}$ The program took place at a mixed gender, residential (four to six months), half-way house for working age adults for 120 residents. At discharge, participants demonstrated elevated occupational performance, self-esteem, and quality of life as measured by the Occupational Performance History Interview (OPHI-II), the Rosenburg Self-Esteem Scale (RSES), and the Quality of Life Rating (QOLR) scale. ${ }^{16}$

\section{The REP Intervention}

A five-week psycho-education group entitled "The Taking Control Challenge" was developed by the two students. Psychoeducation groups have been utilised by clinicians for decades. ${ }^{12}$ Its supportive approach has been found to be effective in improving self-esteem, coping, and self-efficacy of women who have been physically abused. ${ }^{18}$ The group's aims were to provide participants with an increased understanding of their problems and experiences from an occupational and psychological perspective. New skills and coping strategies, including mindfulness and cognitive behavioural therapy techniques, were utilised to support coping. It was hypothesised this would have a positive impact on participants' occupation and self-esteem. Topics covered included the fight or flight response, assertiveness, the links between thoughts, feelings and behaviours, effective communication, and the use of self-rating to help manage stress and anger. Role play and homework was incorporated into the sessions so as to reinforce the acquisition and practice of new skills. Table 1 outlines each session, its content and homework.

Table 1: Take Control Course Content

\begin{tabular}{|lll|}
\hline Week & \multicolumn{1}{c|}{ Subject Matter } & \multicolumn{1}{c|}{ Homework } \\
\hline 1 & $\begin{array}{l}\text { Introduction, ice breaker, establishment of group rules and confidentiality. } \\
\text { Complete Rosenburg Self-Esteem measure. Mindfulness, introduction of } \\
\text { cognitive triad, introduction to fight or flight }\end{array}$ & $\begin{array}{l}\text { Try mindfulness meditation at } \\
\text { home. }\end{array}$ \\
\hline 2 & $\begin{array}{l}\text { Overview, homework review, re- establishment of group rules. } \\
\text { Identify how thoughts and feelings can impact on behaviours. } \\
\text { Identification of flight or flight sensations negative and positive coping. }\end{array}$ & $\begin{array}{l}\text { Practice different strategies } \\
\text { taught in session. Find a } \\
\text { motivational quote to support a } \\
\text { friend in need. }\end{array}$ \\
\hline 3 & $\begin{array}{l}\text { Overview, homework review, re- establishment of group rules. } \\
\text { Relate negative coping to own triggers. Introduce self-rating and time } \\
\text { out. Teach and practice breathing techniques (deep breathing and } \\
\text { pursed lip breathing). Use homework quote to support self. }\end{array}$ & $\begin{array}{l}\text { Practice the progressive muscle } \\
\text { relaxation and breathing } \\
\text { techniques. }\end{array}$ \\
\hline $\mathbf{4} \quad \begin{array}{l}\text { Overview, homework review, re- establishment of group rules. } \\
\text { Assertiveness, difference between passive, assertive and aggressive } \\
\text { behaviour. Introduction of strategies to become more assertive. }\end{array}$ & $\begin{array}{l}\text { Review list of assertiveness } \\
\text { rights and write down those you } \\
\text { find most difficult to assert and } \\
\text { why. }\end{array}$ \\
\hline $\mathbf{5}$ & $\begin{array}{l}\text { Overview, homework review, re- establishment of group rules. } \\
\text { Complete Rosenburg Self-Esteem scale. Accepting positive feedback } \\
\text { and how to take criticism. Goal setting. Quiz on information from the past } \\
\text { 4 sessions. Certificate hand-out. }\end{array}$ & \\
\hline
\end{tabular}

\section{Outcome Measures}

The Rosenberg Self Esteem Scale (RSES), administered in the first and last session, was used as an outcome measure of the group's effectiveness. ${ }^{19}$ Self-esteem is notoriously difficult to measure because it can be complicated with narcissism and ego defence; thus, objective measures such as the RSES are recommended. ${ }^{20}$ The RSES is a 10-item Likert scale that measures global self-worth. Scores between 15 and 25 are within normal range, while scores below 15 suggest low self-esteem. ${ }^{19}$ The measure specifically addresses self-satisfaction, self-worth, self-respect and personal pride esteem. ${ }^{16}$ The students chose the RSES because of its established psychometric properties and reliability as a measure of adult self-esteem, it is quick to administer, and its simple language would be easy for participants to understand. ${ }^{16}$

\section{RESULTS}

\section{Outcomes}

Eight women participated in the group. Of this eight, all participated in four or more sessions and three participated in every session. The pre/post-test results indicated an overall increase in self-esteem, as measured by the RSES of $19 \%$ for the whole group, and every participant's score increased. The overall percentage score increase was the product of the overall mean pretest RSES scores subtracted from the mean post-test RSES scores. The students chose to use the percentage scores because

(C) The Internet Journal of Allied Health Sciences and Practice, 2017 
they considered them to be a more meaningful and appropriate way to explain the results to participants. The scores were presented to participants in the last session, but were not otherwise recorded by the students, and therefore are not available for reproduction in this paper. All participants self-reported that their knowledge had increased and that they would use the strategies learned in the future. One participant said she was extremely proud of herself and that the scores have "motivated me to continue using the techniques."

\section{The Student Experience}

The students reported the REP to be a great opportunity for building their confidence and developing a deeper understanding of occupational therapy, stating "It makes you think more creatively about how much we can offer as therapists." The placement helped students to innovate in response to service user need, assured in their professional role and core skills. One student stated "It gives you a great confidence to go into an organisation and identify a need for occupational therapy and to work independently to develop a solution to that need."

The students also found the placement challenging. They described the coffee mornings as boisterous affairs and worried about how these older and worldlier women would take to receiving instruction and being given homework from occupational therapy students. The students made the decision to formalise the intervention. This was to create a different learning environment as compared to the coffee mornings and to highlight the serious nature of what the group would cover. The students collaboratively established group goals with the women, ensured each session had defined learning outcomes, and used power point slides to support the learning of new knowledge. The students also decided to be upfront and frank about themselves and to acknowledge with the group their youth and fears about being facilitators. One student reported that "The women took us seriously; I think because the sessions were done in a serious way."

The students were also concerned about how they would be perceived by the REP site staff. Because they were going to introduce "fancy ideas" and new ways of working, the students worried the staff might feel challenged by this and in response ignore them, patronise their efforts, or pressure them into providing generic work instead. This, amongst other things, was discussed with the onsite and fieldwork educator in weekly supervision sessions. Worries and concerns were identified and strategies to correct or nullify them were developed. The on-site supervisor, with her in-house knowledge, provided invaluable support in supervision sessions. Most of the student's concerns did not come to fruition, and the students described the staff as very supportive and interested in the students' work.

\section{The Role-Emerging Placement}

The placement helped contribute to the emergence of occupational therapy in a non-traditional setting and fulfilled the requirement that it leaves a legacy to the service. One student stated "I feel it gives you the confidence to consider non-traditional settings as a future job in occupational therapy. You start looking at other organisations and are able to see the need for occupational therapy there as well."

The centre provided feedback that identified the students' professional approach to their work as the most significant contribution to the centre. The onsite supervisor stated that "The students were able to focus in on a particular need and to meet that need in a very professional way but also in a way that really help the ladies." Following the end of the placement, one of the students was employed, on a sessional basis by the centre, to co-facilitate the group again and at another satellite centre in the same geographical area.

\section{DISCUSSION}

The REP described in this paper took place in a non-governmental organisation, in a community setting. It involved a psychosocial intervention to support, develop, and promote the occupational functioning of female service users who have experienced domestic violence. Issues such as low self-esteem, decreased occupational engagement, and poor adaptive coping were identified by the students in collaboration with service users as barriers to function and meaningful occupation. The results of this project were similar to those found in the literature. Objectively, self-esteem improved as measured by the RSES, and the literature supports the belief that improved self-esteem can have a real impact on life events. ${ }^{21}$ Subjectively, the group participants reported an increase in their knowledge and understanding and stated that they would use the strategies learned in the future.

The service found the clinical approach and professionalism of the students to be key contributors to service delivery. The students provided a specific intervention to meet the expressed needs of service users which is one of the key service objectives of the host organisation. The aims of the program were to provide participants with an increased understanding of their problems

() The Internet Journal of Allied Health Sciences and Practice, 2017 
and experiences from an occupational and psychological perspective. The students did not expressly discuss occupation with attendees but used examples of how specific behaviours, thoughts, and feelings can influence what happens, and that by taking control of their behaviour, attendees can make positive changes to their lives.

The placement was deemed to be a success because the students achieved the just right challenge, a careful balance of task demand and performance skills. The psychosocial intervention was not too complicated or long; it was serious but without the intimidation of a classroom environment and it struck a chord with the participants. The students believed the first session, although the least attended, was the most important because the women at this session gave the thumbs up to the others, who then started to attend. The psychosocial group "The Take Control Challenge" has now been implemented at the REP site as well as another satellite site. This is testament to the program's success, of its relevance to the service, and its intention to meeting the needs of its users.

\section{Recommendations and Limitations}

If the REP intervention described in this paper was to be replicated, the students and supervisors would like to make the following recommendations:

1. The collection of demographic and psychometric data would enable more complex analysis of the results.

2. In addition to the assessment of self-esteem, it would be useful to also assess occupation, for example, collecting MoHST scores before and after intervention.

3. The provision of follow-up courses and collection of outcome measures at three and six months' post intervention might provide additional illuminating information. Cage investigation found occupational performance, self-esteem, and quality of life declined at three months' post-intervention and rose again at six months. ${ }^{16}$ Follow-up sessions could potentially protect against this decline and also help consolidate the use of skills learnt in session.

\section{CONCLUSION}

Role-emerging placements are important for the development of the occupational therapy profession and workforce. Occupational therapists have unique skills, knowledge, and values that can benefit non-government organisations, offering the real possibility of improving their service delivery and user engagement. ${ }^{22}$ In order for occupational therapists to find work in such services, the non-traditional organisations need to understand the value and scope that occupational therapy can offer. ${ }^{22}$ Role-emerging placements are designed to promote the role of occupational therapy as students explore the potential for the profession in emerging practice. 7,9 By focusing on occupation, students also draw on the roots of the profession and anchor its future to the theoretical foundations of its past. Role emerging-placements therefore straddle current and future practice and provide an interface between the profession, potential employers, and future workforce development. $6-8$

\section{REFERENCES:}

1. Davis J. The importance of the community of practice in identity development. IJAHSP. 2006:4(3). Available from: http:/lijahsp.nova.edu/articles/vol4num3/davis.htm

2. Thew M, Hargreaves A, Cronin-Davis J. An evaluation of a role-emerging practice placement model for a full cohort of occupational therapy students. BJOT. 2008;71:348-53.

3. Fieldhouse J, Fedden T. Exploring the learning process on a role-emerging practice placement: a qualitative study. BJOT. 2009;72(7):302-7.

4. Clarke C, Martin M, Sadlo G, De Visser R. The development of an authentic professional identity on role-emerging placements. British J Occup Ther. 2014;77(5):222-9.

5. Thomas Y, Penman M, Williamson P. Australian and New Zealand fieldwork: Charting the territory for future practice. Aust Occup Ther J. 2005;52:78-8.

6. Overton A, Clark M, Thomas Y. A review of non-traditional occupational therapy practice placement education: a focus on role-emerging and project placements. British J Occup Ther. 2009;72(7):294-301.

7. Boniface G, Seymour A, Polglase T, Lawrie C, Clarke M. Exploring the nature of peer and academic supervision on a roleemerging placement. British J Occup Ther. 2012;75(4):196-201.

8. Dancza K, Warren A, Copley A, Rodger S, Moran M, McKay E, Taylor A. Learning experiences on role-emerging placements: an exploration from the students' perspective. Aust Occup Ther J. 2013;60(6):427-35. [PMID: 24299482]

9. Cooper R, Raine R. Role-emerging placements are an essential risk for the development of the occupational therapy profession: the debate. British J Occup Ther. 2009;72(9):416-8.

10. Thomas Y, Penman M, Williamson P. Australian and New Zealand fieldwork: Charting the territory for future practice. Aust Occup Ther J. 2005;52:78-8.

(C) The Internet Journal of Allied Health Sciences and Practice, 2017 
11. Thew M, Edwards M, Baptise S, Molineux M. Role Emerging Occupational Therapy: Maximising Occupation-Focused Practice, 1e. Blackwell Publishing Limited, Wiley-Blackwell, Chichester; 2011.

12. College of Occupational Therapists. Developing the Occupational Therapy Profession: Providing new work-based learning opportunities for students. College of Occupational Therapists Guidance 4; 2006, London: COT.

13. Colom F, Vieta E, Martínez-Arán A, Reinares M,Goikolea J, et al. A randomized trial on the efficacy of group psychoeducation in the prophylaxis of recurrences in bipolar patients whose disease is in remission. Arch Gen Psychiatry. 2003;60,402-7. Available from http://archpsyc.jamanetwork.com/article.aspx?articleid=207340 [PMID:12695318]

14. Bennett L, Riger S, Schewe P, Howard A, Wasco S. Effectiveness of hotline, advocacy, counseling, and shelter services for victims of domestic violence a statewide evaluation." J Interpers Violence. 2004;19(7):815-29. [PMID: 15186538]

15. Gorde M, Helfrich C, Finlayson M. Trauma Symptoms and Life Skill Needs of Domestic Violence Victims. J Interpers Violence. 2005;19(6):691-708. [PMID: 15140319]

16. Cage A. Occupational Therapy with Woman and Children Survivors of Domestic Violence: Are We Fulfilling Our Activist heritage? A review of the Literature. British J Occup Ther. 2007;70(5):192-8.

17. Cascardi M, O'Leary KD. Depressive symptomatology, self-esteem, and self-blame in battered women. $J$ Interpers Violence. 1992;7:249-59.

18. Waldrop A, Resick P. Coping among adult female victims of domestic violence. J Family Violence. 2004;19(5):291-302

19. Rosenberg M. Society and the Adolescent Self-image. Princeton, NJ: Princeton University Press; 1965.

20. Gray-Little B, Williams V, Hancock T. An item response theory analysis of the Rosenberg Self-Esteem Scale. Personality and Social Psychology Bulletin. 1997;23:443-51.

21. Orth U, Robins RW, Widaman KF. Life-span development of self-esteem and its effects on important life outcomes. J Pers Soc Psychol. Jun 2012;102(6):1271-88. [PMID: 21942279]

22. Klinger $\mathrm{K}$, Bossers $\mathrm{A}$. Contributing to operations of community agencies through integrated fieldwork experiences. Can J Occup Ther. June 2009;76(3):171-9. [PMID:19630307] 